УДК 669.24.002.8:621.01

Клочихин В. В. ${ }^{1}$, Рудъ Н.Д.', Наумик В. В. ${ }^{2}$, Чигилейчик Е. В. ${ }^{1}$

${ }^{1}$ АО «Мотор Сич». Украина, г. Запорожье

2 Запорожский национальный технический университет. Украина, г. Запорожье

\title{
ВЛИЯНИЕ ВЕКТОРА СПЛАВЛЕНИЯ ПОРОШКА НА СВОЙСТВА ОБРАЗЦОВ, ИЗГОТОВЛЕННЫХ ПО АДДИТИВНОЙ ТЕХНОЛОГИИ
}

В данной работе проведены исследования влияния вектора сплавления титанового порошка на свойства образц,о, изготовленных по аддитивной технологии ЕВМ (Electron Beam Melting). Показаны преимущества технологии сплавления порошков из титановых сплавов посредством электронного луиа в вакууме. Анизотропия прочностных и пластических свойств испытаниями не установлена. Значения ударной вязкости были существенно выше для образцов, сплавленных в направлении оси Z. По результатам исследований выданы рекомендации по использованию технологии ЕВМ в авиадвигателестроении с оптимизацией выбора вектора сплавления при изготовлении заготовок из титановых сплавов. [dx.doi.org/10.29010/080.9]

Ключевые слова: аддитивные технологии; титановые порошки; вектор сплавления; анизотропия свойств. 


\section{Введение}

Для деталей изготавливаемых различными методами литья характерны ликвационные дефекты, развивающиеся в процессе кристаллизации расплава в форме. Ликвационные процессы порождают химическую неоднородность, усадочную пористость и как следствие анизотропию свойств по сечениям отливки.

Инженеры и ученые создали множество технологических разработок для минимизации ликвационных процессов, но разработка и внедрение аддитивных технологий устраняет саму причину данной проблемы [1,2].

Для аддитивных технологий применяют порошки дисперсностью от 20 до 100 мкм, получаемые методами газового распыления (gas atomization) или центробежным разбрызгиванием (PREP Plasma Rotation Electrode Process) [3, 4]. Скорость охлаждения при получении сферических гранул приведенной дисперсности для указанных процессов изготовления составляет от $10^{3}$ до $10^{6} \mathrm{~K} /$ сек $[5,6]$. В таких условиях кристаллизации процессы ликвации не развиваются, что и является одним из основных преимуществ аддитивных технологий с точки зрения формирования структуры изделия $[7,8]$.

Второе преимущество - неограниченная возможность формообразования геометрически сложных деталей. Однако при построении таких деталей неоднократно меняется вектор движения лазерного или электронного луча в системе координат XYZ при послойном селективном сплавлении порошка в различных частях детали $[9,10]$.

В данной работе проведены исследования влияния вектора сплавления титанового порошка на свойства образцов, изготовленных по аддитивной технологии.

\section{Материалы и методы эксперимента}

Опытные образцы были изготовлены фирмой Arcam по аддитивной технологии EBM (Electron Beam Melting), сущность которой заключается в сплавлении порошка под воздействием электронного луча в вакууме при остаточном давлении не более $1 \times 10^{-4}$ мбар.

В качестве материала для изготовления образцов был выбран титановый сплав Ti6AL4V, хорошо изученный в производстве отливок, штамповок, сварных листовых узлов. В настоящее время находятся в процессе активного освоения атомайзинг порошков и аддитивное производство деталей из данного сплава $[11,12]$. Для сплавления заготовок были использованы порошки из сплава Ti6AL4V с содержанием кислорода до $0,2 \%$ и Ti6AL4V ELI с содержанием кислорода до $0,13 \%$.
Технология ЕВМ обеспечивает стабильность качества изделий из титановых сплавов по плотности и структурной однородности материала, в отличие от технологий сплавления лазером в среде аргона, в которых не исключается насыщение титана кислородом и азотом, приводящим к снижению его пластичности.

В процессе исследования опытных образцов проводили осмотр рельефа поверхности под бинокулярным микроскопом, определяли химический состав, механические свойства, изучали макрои микроструктуру.

Для проведения испытаний на механические свойства была выбрана простая форма образцов: «пальчиковые» - для испытания на разрыв и образцы квадратного сечения с минимальным припуском на механическую обработку - для определения ударной вязкости.

\section{Основной материал исследований}

Выбранная геометрия образцов позволила осуществлять их изготовление в соответствии с заданными векторами построения. Внешний вид образцов, построенных в направлении XY и Z, приведен на рис. 1.

Визуальный и осмотр под бинокулярным микроскопом показал, что рельеф различных поверхностей образцов, полученных по аддитивной технологии EBM, не идентичен. Он характеризуется как мелкобугристым (рис. 2, а), так и строчечным разнонаправленным (бороздчатым) строением, с оплавленным крайним слоем (рис. 2, б). Представленный рельеф поверхностей опытных образцов обусловлен разными векторами их сплавления.

Анализ химического состава опытных образцов по легирующим элементам выполнялся на спектрометре ARL4460, по газовым примесям кислороду и азоту на газоанализаторе LECO TC500, а по углероду - LECO CS230 (табл. 1).

В табл. 1 также приведены нормы для порошков сплава Ti6Al4V и, для сравнения, ближайшего отечественного аналога - литейного сплава ВТ6Л согласно ОСТ 1.90013-81.

Заданные нормы по химическому составу для порошков Ti6Al4V имеют более узкий интервал по содержанию легирующих элементов и более жёсткие требования по допустимым примесям $\mathrm{O}_{2}$, $\mathrm{N}_{2}$ и С, в сравнении с литейным сплавом ВТ6Л согласно ОСТ 1.90013-81.

Установлено, что в фактически изготовленных по аддитивной технологии ЕВМ образцах содержание примесей ниже требований нормативно-технической документации для сплава-аналога ВТ6Л по кислороду в 1,8 раза, углероду - в 2,5 раза и азоту в $-6,5$ раз. 


\section{СИСТЕMЫTC 3/2017}
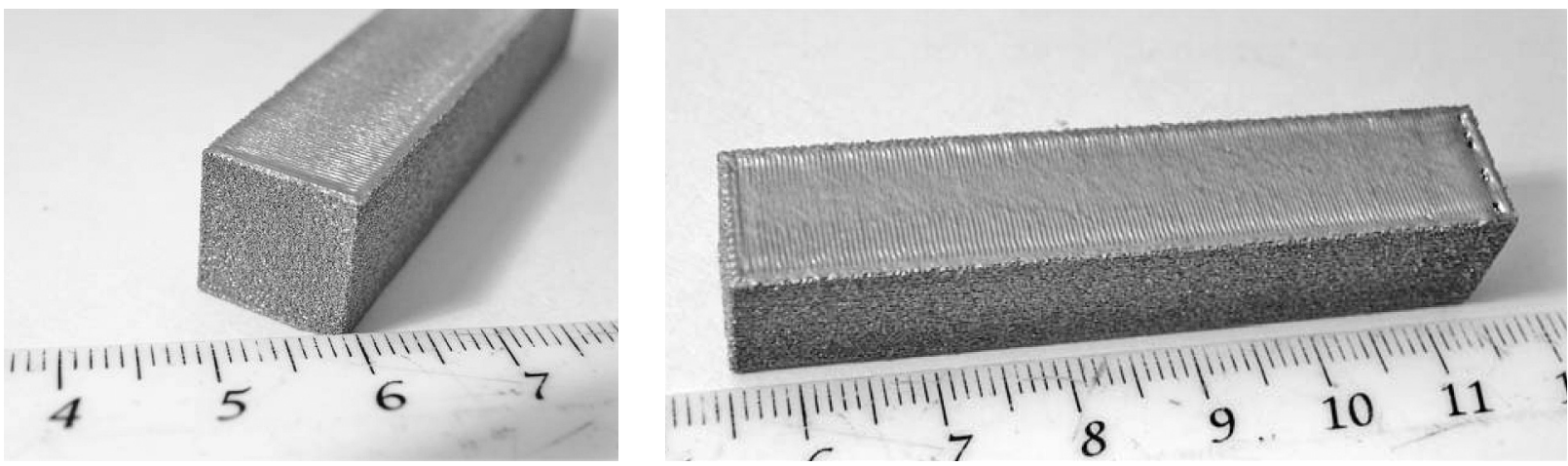

a
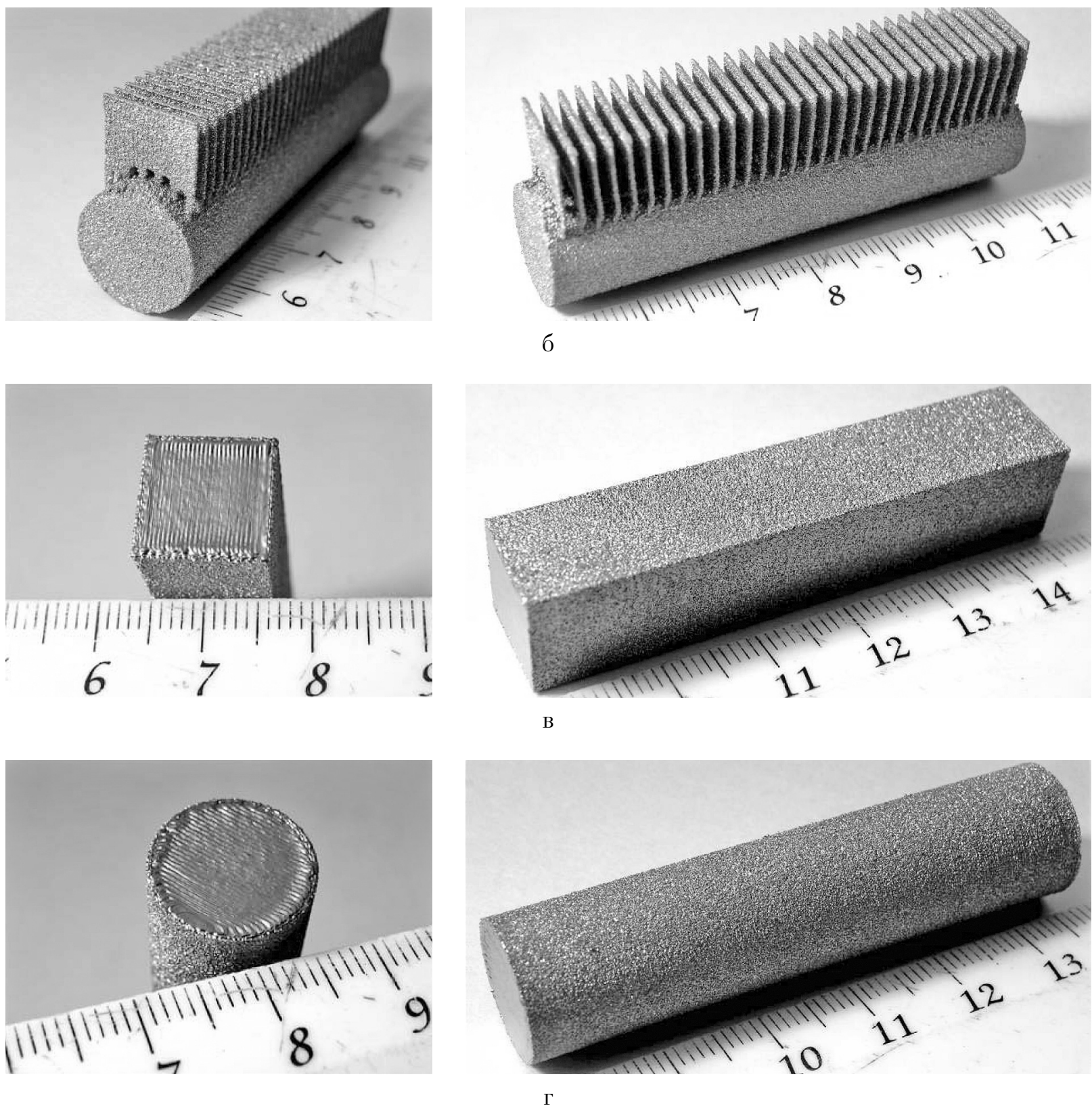

Рис. 1. Внешний вид образцов, сформированных:

a, 6 - в направлении XY; в, г - в направлении Z 


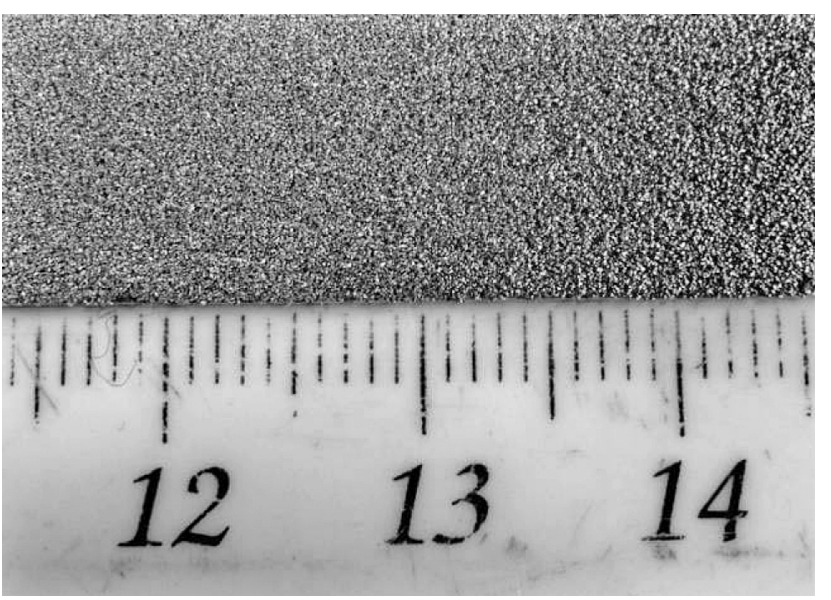

a

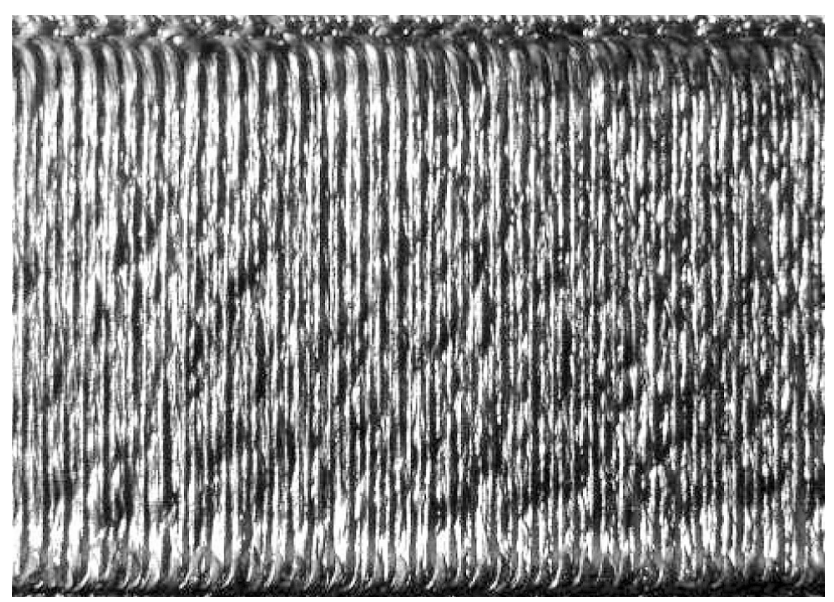

б

Рис. 2. Рельеф поверхностей образцов, полученных по аддитивной технологии ЕВМ

Механические свойства определялись, как в исходном состоянии, так и после термообработки на образцах, сформированных в направлениях XY и Z. Термообработка образцов осуществлялась по типовому режиму неполного отжига: температура нагрева $750 \pm 10^{\circ} \mathrm{C}$ в застойной атмосфере аргона, время выдержки 1,5 час \pm 10 мин, охлаждение на воздухе. В табл. 2 для сравнительного анализа приведены значения механических свойств образцов, полученных сплавлением порошка сплава Ti6AL4V и нормы свойств для ближайших аналогов: деформированного сплава ВТ6 (ОСТ $190002-$ 70) и литейного ВТ6Л (ОСТ 1 90060-92).

Анализ приведенных данных свидетельствует о том, что механические свойства образцов из сплавленного порошка Ti6AL4V $\left(\sigma_{\mathrm{s}} ; \sigma_{02} ; \delta ; \Psi ; \mathrm{HRC}\right)$ имеют равномерные значения, анизотропия свойств для разных направлений сплавления XY и $\mathrm{Z}$ отсутствует.

Значения КСU для образцов, сплавленных в направлении оси $\mathrm{Z}$ выше, чем значения для образ- цов, сплавленных по осям XY на 48,3\% до термообработки. Существенная разница сохранилась и после термообработки $-27,3 \%$.

Структуру оценивали по темплетам, изготовленным в поперечном сечении образцов. Травление образцов осуществлялось в реактиве, состоящем из смеси плавиковой, соляной кислот и глицерина.

Микроструктуру изучали с помощью растрового электронного микроскопа JEOL JSM-IT300 LV, оснащенного системой рентгеноспектрального микроанализа (PCMA) X-Max 80 фирмы Oxford Instruments.

Проведено сравнительное исследование образцов, полученных сплавлением порошка $\mathrm{Ti} 6 \mathrm{Al} 4 \mathrm{~V}$ по аддитивной технологии ЕВМ и образцов деформированного сплава ВТ6 (поковка штампованная) в термообработанном состоянии (рис. 3,4$)$. Установлено, что образец из сплавленного порошка Ti6Al4V (аддитивная технология EBM) имеет однородную мелко игольчатую микроструктуру,

Таблица 1

Химический состав образцов, изготовленных по аддитивной технологии ЕВМ

\begin{tabular}{|c|c|c|c|c|c|c|c|c|}
\hline \multirow{2}{*}{ Источник } & \multicolumn{8}{|c|}{ Содержание элементов, \% по массе } \\
\hline & Ti & Al & $\mathbf{F e}$ & $\mathrm{Si}$ & $\mathbf{V}$ & $\mathbf{O}_{2}$ & $\mathbf{N}_{2}$ & C \\
\hline $\begin{array}{l}\text { Ti6Al4V, образец } \\
\text { сплавленный ЕBM }\end{array}$ & \multirow{3}{*}{ 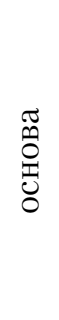 } & 5,60 & 0,17 & следы & 3,83 & 0,11 & 0,00769 & 0,04 \\
\hline $\begin{array}{c}\text { Нормы для порошков } \\
\text { Ti6Al4V }\end{array}$ & & $5,50-6,50$ & $\leq 0,25$ & - & $3,50-4,50$ & $\leq 0,13$ & $\leq 0,03$ & $\leq 0,08$ \\
\hline $\begin{array}{l}\text { Нормы для ВТ6Л } \\
\text { (ОСТ 1.90013-81) }\end{array}$ & & $5,30-6,80$ & $\leq 0,30$ & $\leq 10$ & $3,50-5,30$ & $\leq 0,20$ & $\leq 0,05$ & $\leq 0,10$ \\
\hline
\end{tabular}




\section{Механические свойства опытных образцов}

\begin{tabular}{|c|c|c|c|c|c|c|}
\hline $\begin{array}{c}\text { Технология } \\
\text { изготовления } \\
\text { образцов }\end{array}$ & \multicolumn{4}{|c|}{$\begin{array}{c}\text { Сплавление титанового порошка электронным } \\
\text { лучом в вакууме (EBM) }\end{array}$} & Штамповка & $\begin{array}{c}\text { Центробежное } \\
\text { литье }\end{array}$ \\
\hline Сплав & \multicolumn{4}{|c|}{ Ti6AL4V } & BT6 & ВТ6Л \\
\hline Состояние & \multicolumn{2}{|c|}{ Без термообработки } & \multicolumn{2}{|c|}{ После термообработки } & Отжиг & ГИП \\
\hline $\begin{array}{l}\text { Направление } \\
\text { формирования }\end{array}$ & $\mathrm{XY}$ & $\mathrm{Z}$ & $\mathrm{XY}$ & $\mathrm{Z}$ & & \\
\hline \multirow{2}{*}{$\begin{array}{c}\text { Предел прочности } \\
\sigma_{\text {в }}, \text { кгс } / \text { мм }^{2}\end{array}$} & 105,0 & 97,3 & 107,0 & 104,3 & \multirow{2}{*}{$85 \ldots 107$} & \multirow{2}{*}{$90 \ldots 110$} \\
\hline & 105,0 & 95,3 & 104,0 & 95,4 & & \\
\hline \multirow{2}{*}{$\begin{array}{c}\text { Предел текучести } \\
\sigma_{0,2}, \text { кг } / \text { мм }^{2}\end{array}$} & 88,8 & 82,5 & 89,2 & 87,7 & & \multirow{2}{*}{$\geq 81$} \\
\hline & 87,6 & 82,5 & 86,2 & 86,2 & & \\
\hline \multirow{2}{*}{$\begin{array}{l}\text { Удлинение }^{\text {длие }} \\
\delta, \%\end{array}$} & 15,2 & 14,8 & 15,2 & 12,8 & \multirow{2}{*}{$\geq 6$} & \multirow{2}{*}{$\geq 5$} \\
\hline & 14,8 & 15,6 & 16,0 & 13,2 & & \\
\hline \multirow{2}{*}{$\begin{array}{l}\text { Поперечное } \\
\text { сужение } \psi, \%\end{array}$} & 29,7 & 39,2 & 32,8 & 29,7 & \multirow{2}{*}{$\geq 20$} & \multirow{2}{*}{$\geq 10$} \\
\hline & 32,8 & 40,7 & 33,1 & 36,3 & & \\
\hline \multirow{2}{*}{$\begin{array}{l}\text { Ударная вязкость } \\
\text { KCU, кгсм/мм² }\end{array}$} & 3,88 & 6,38 & 3,88 & 5,0 & \multirow{2}{*}{$\geq 3,0$} & \multirow{2}{*}{$\geq 2,5$} \\
\hline & 4,13 & 5,50 & 3,88 & 4,88 & & \\
\hline Твердость HRC & $32,5 \ldots 33,0$ & $32,0 \ldots 33,5$ & $32,5 \ldots 33,5$ & $34,5 \ldots 34,0$ & $35,0 \ldots 43,5$ & $35,0 \ldots 39,0$ \\
\hline
\end{tabular}

характерную для мартенситного превращения при быстром охлаждении из $\beta$ области, что и обеспечивает оптимальное сочетание прочности, пластичности и вязкости разрушения. Образец деформированного сплава ВТ6 (поковка штампованная) имеет смешанную структуру, состоящую из первичных зерен $\alpha$ фазы и $\beta$ превращенной тонкопластинчатой матрицы $((\alpha+\beta)$ зерна).

По данным РСМА химический состав структурных составляющих в образце из сплава ВТ6 (поковка штампованная) различен, $\alpha$-фаза содержит повышенное количество $\mathrm{Al}$, a $\mathrm{V}$ сосредоточен в основном в $\alpha+\beta$ фазе (рис. $5, \sigma ; 6)$.

В образце из сплава Ti6AL4V (аддитивная технология ЕВM) РСМА показал другую картину: химический состав однороден на микроуровне содержание $\mathrm{Al}$ и $\mathrm{V}$ одинаково в пределах чувствительности метода (рис. 5, б; 7). Это факт соответствует способу получения материала - моментальное сплавление химически однородных и гранулометрически подобранных частиц для обеспечения максимального заполнения объема.

\section{Выводы}

Механические свойства образцов, изготовленных по аддитивной технологии ЕВМ сплавлением порошков сплава Ti6AL4V по прочности соответствуют нормам для деформированного сплава аналога ВТ6 (ОСТ 1 9002-70) и литейного ВТ6Л (ОСТ 1 90060-92). При этом характеристики пластичности и ударная вязкость сплавленного материала превышают соответствующие нормы в 1,5...2 раза.

При испытании на разрыв образцов с различными векторами сплавления порошка XY и Z анизотропия прочностных и пластических свойств не установлена.

Значения ударной вязкости для образцов, сплавленных в направлении оси Z выше, чем для образцов, сплавленных по осям X и Y на 48,3\%. Существенная разница в данном параметре сохранилась и после термообработки - 27,3\%.

Аддитивная технология ЕВМ может быть рекомендована для изготовления деталей авиационных двигателей вместо титанового литья. После проведения необходимого объема квалификационных 


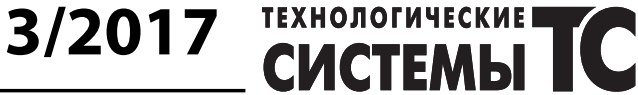

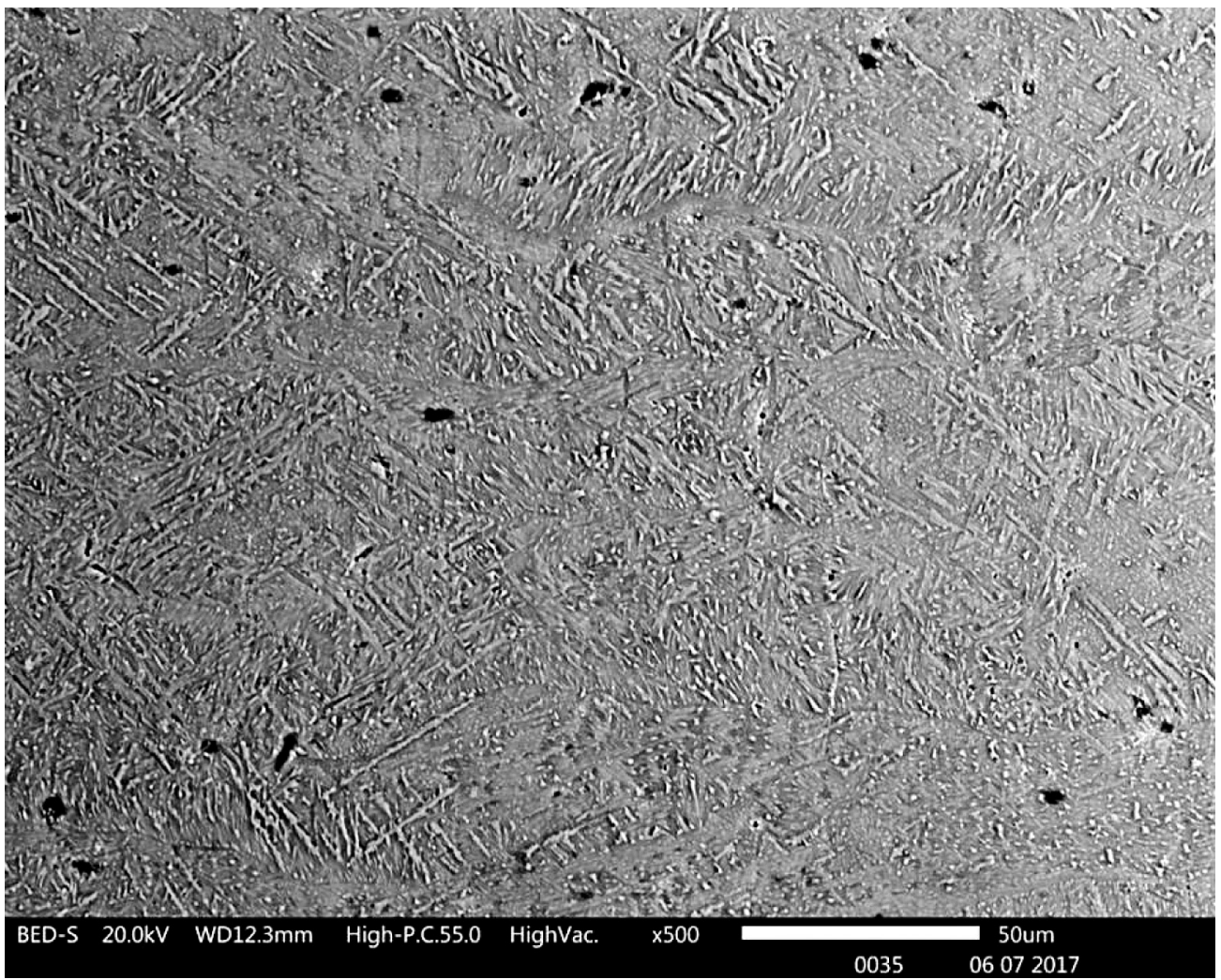

a

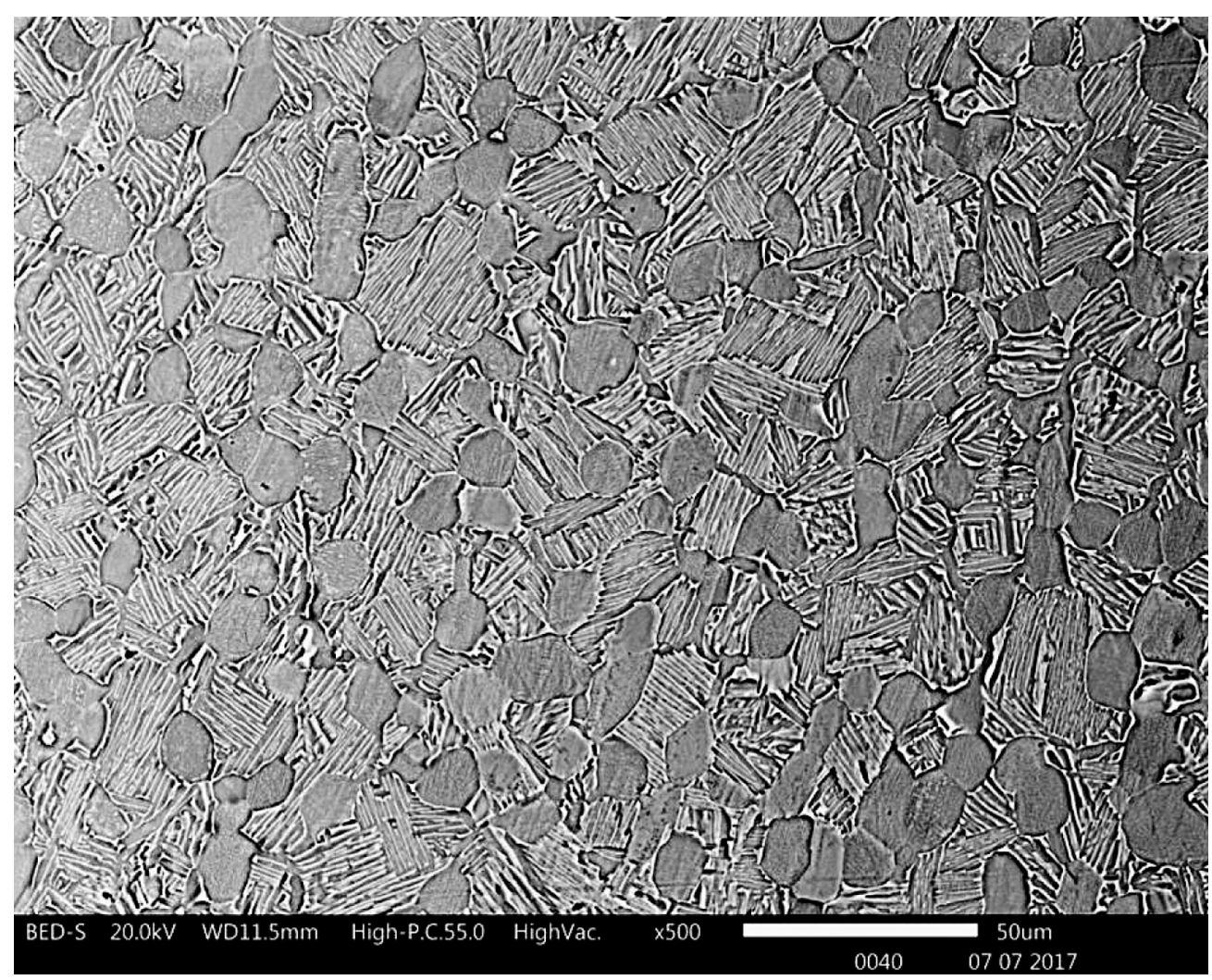

б

Рис. 3. Микроструктура при увеличении $\times 500$ :

$\mathrm{a}-$ сплавленный порошок Ti6Al4V (аддитивная технология EBM);

б - деформированный сплав ВТ6 (поковка штампованная) 


\section{СИСТЕМЫТС 3/2017}

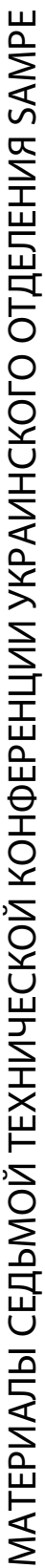
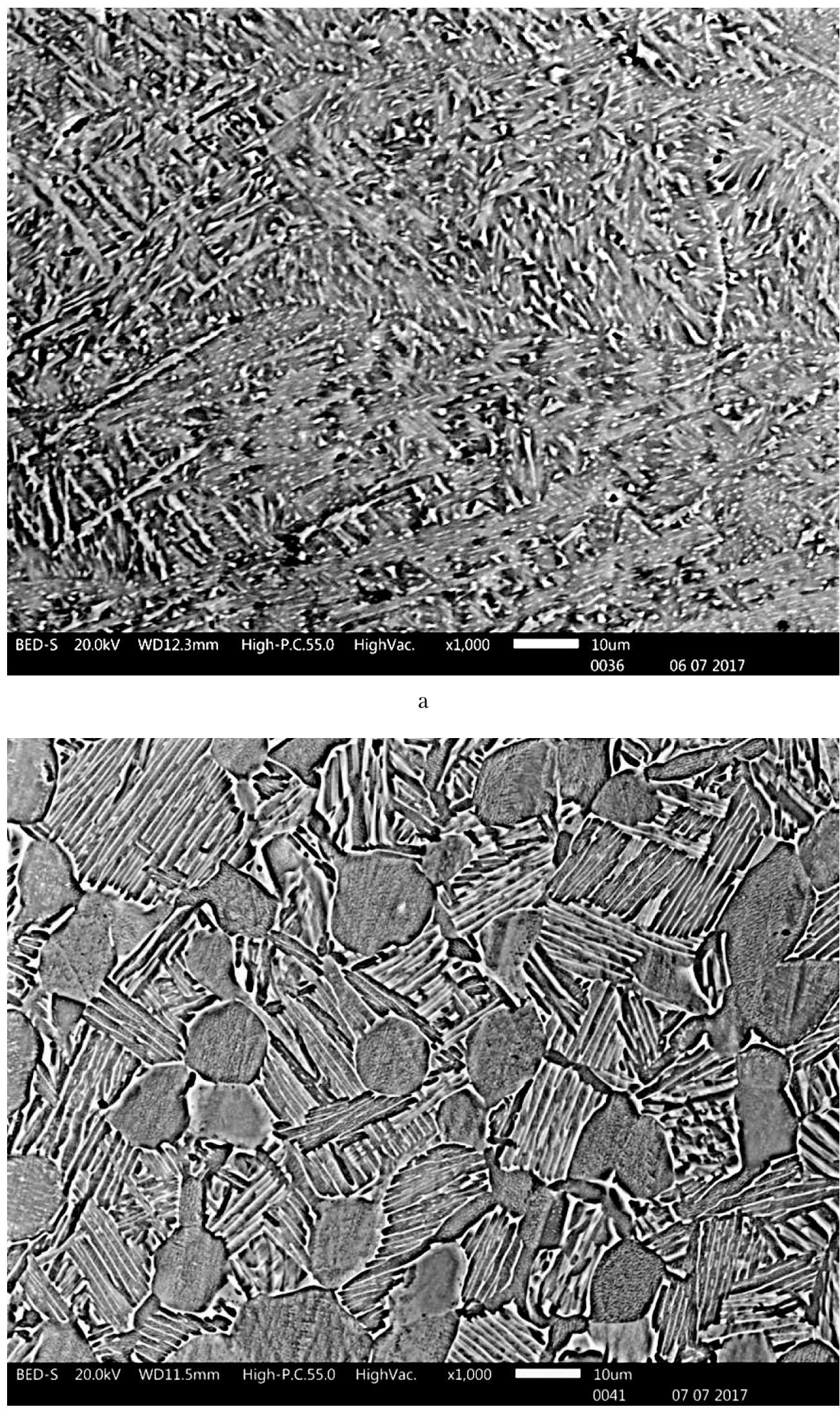

б

Рис. 4. Микроструктура при увеличении $\times 1000$ :

$\mathrm{a}$ - сплавленный порошок Ti6Al4V (аддитивная технология EBM)

б - деформированный сплав ВТ6 (поковка штампованная) 


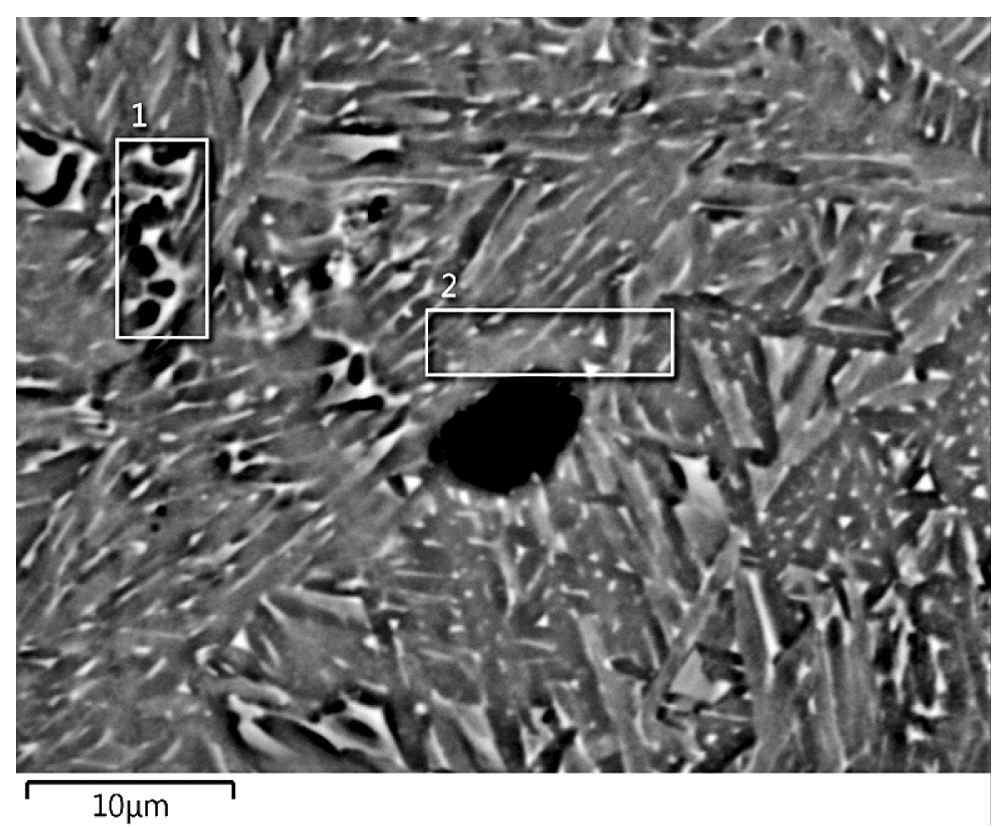

a $\times 2700$

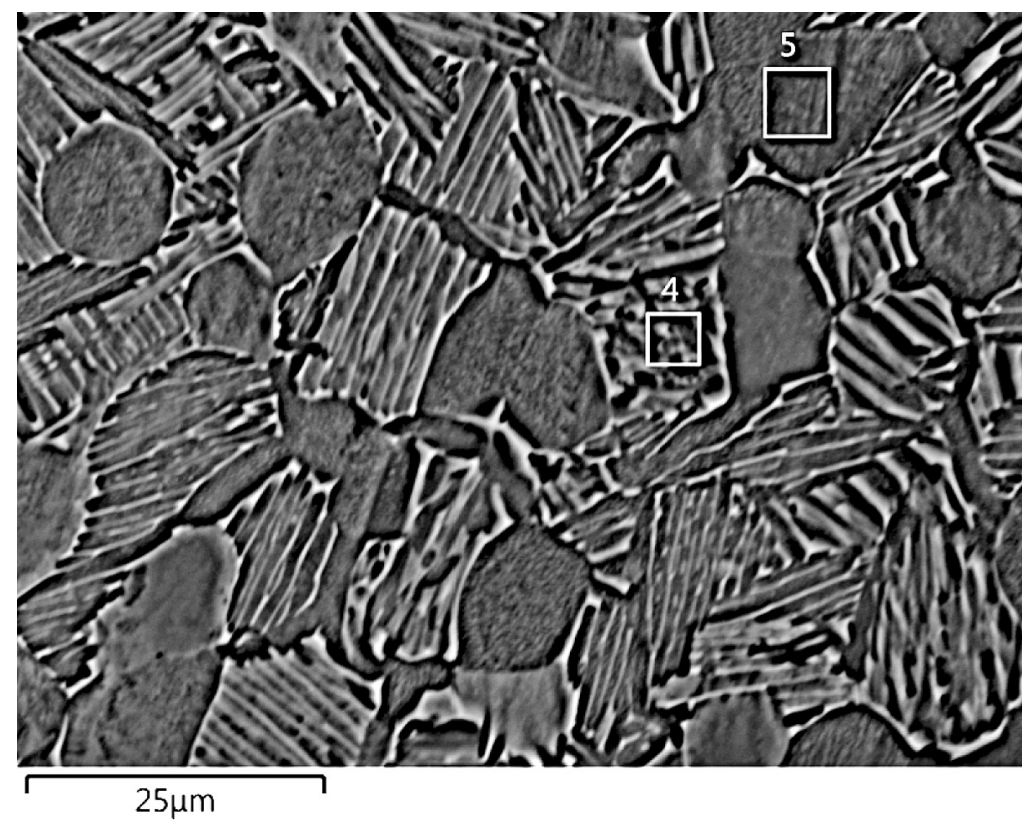

$6 \times 1500$

\begin{tabular}{|c|c|c|c|}
\hline \multirow{2}{*}{ № точки анализа } & \multicolumn{3}{|c|}{ содержание элементов, \% по массе } \\
\cline { 2 - 4 } & $\mathbf{A l}$ & $\mathbf{T i}$ & $\mathbf{V}$ \\
\hline 1 & 5.42 & 90.85 & 3.73 \\
\hline 2 & 5.52 & 90.51 & 3.97 \\
\hline 3 & 5.91 & 88.66 & 5.43 \\
\hline 4 & 7.43 & 90.61 & 1.96 \\
\hline
\end{tabular}

Рис. 5. Микроструктура материала и результаты РСМА в режиме анализа по площади: a - сплавленный порошок Ti6Al4V и места анализа;

б - деформированный сплав ВТ6 и места анализа 


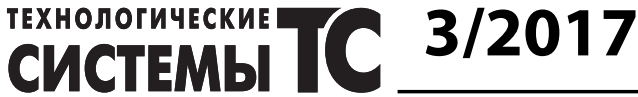

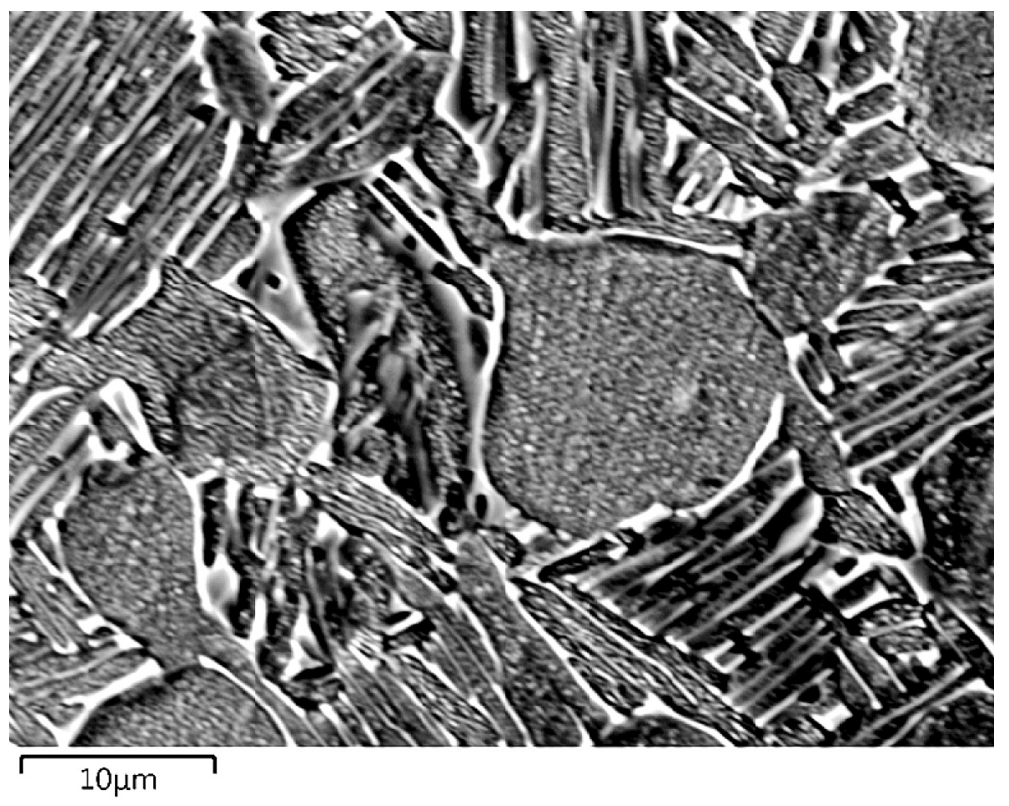

$\times 2500$

\section{Al K серия}

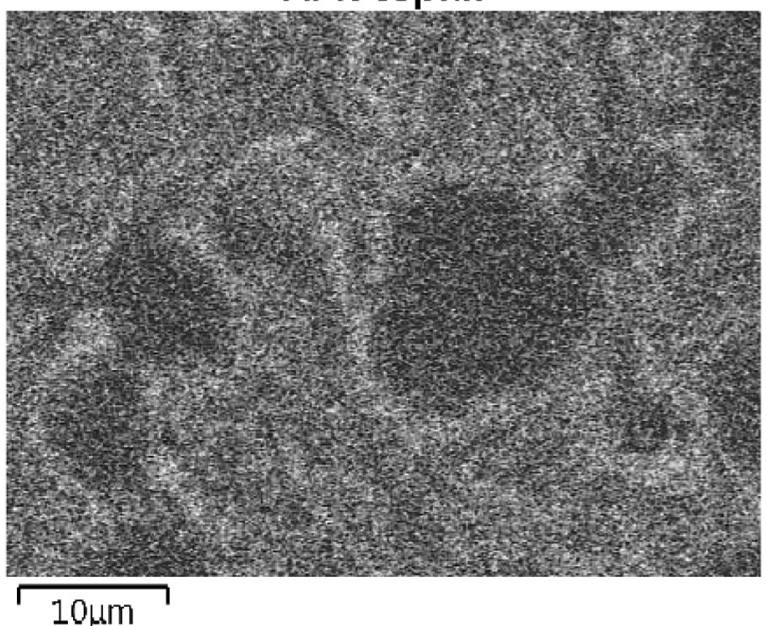

Ті К серия

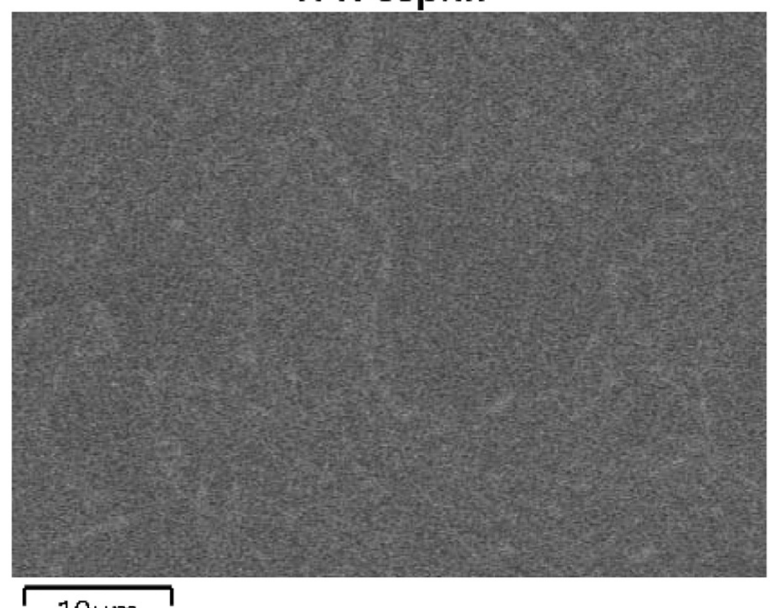

$10 \mu \mathrm{m}$

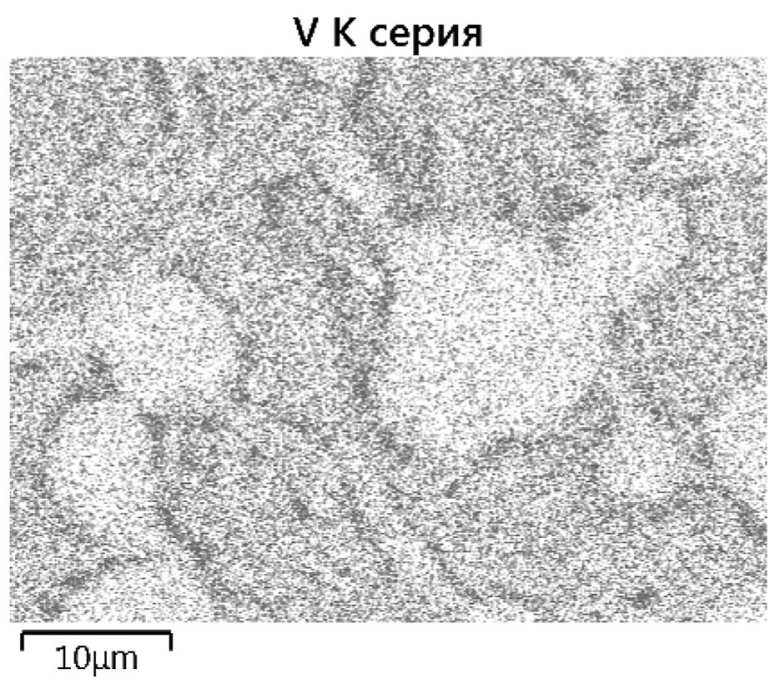

Рис. 6. Результаты РСМА в режиме картирования деформированного сплава ВТ6 (поковка штампованная). Большему содержанию элемента соответствует более интенсивная окраска 


\section{$3 / 2017$}

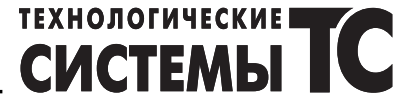

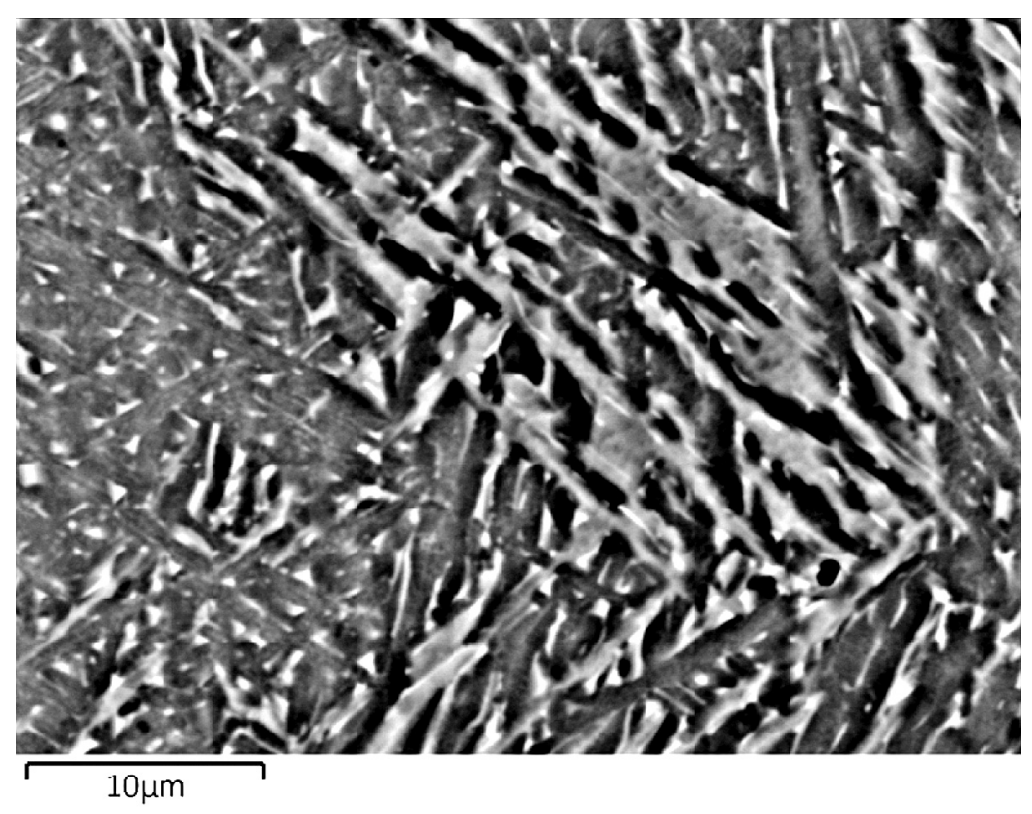

$\times 3000$

\section{Al K серия}

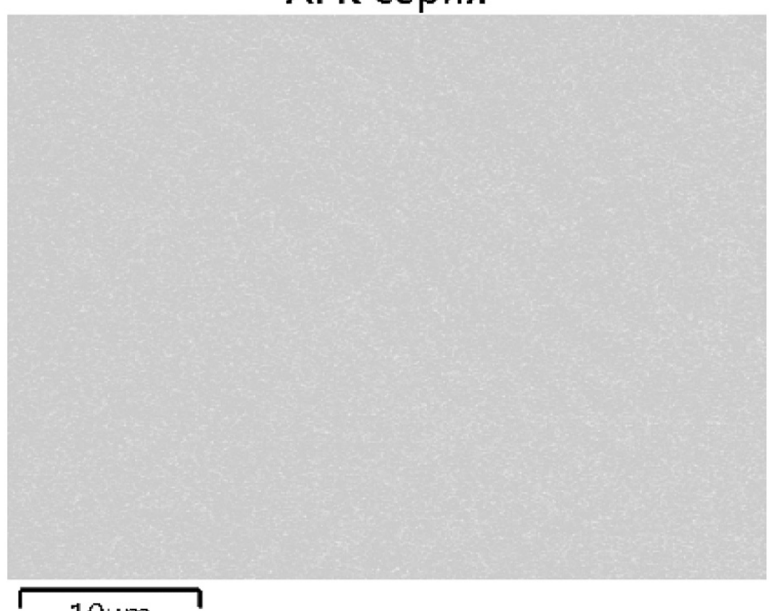

$10 \mu \mathrm{m}$
Ті К серия

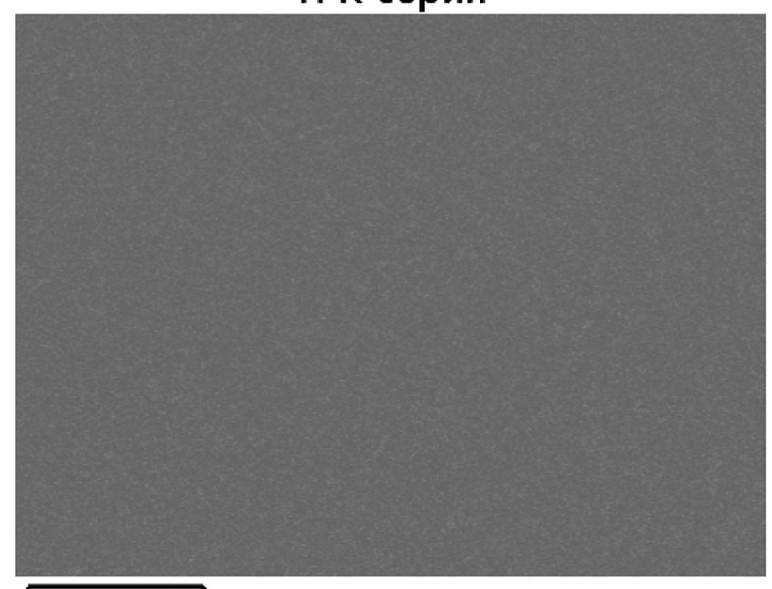

$10 \mu \mathrm{m}$

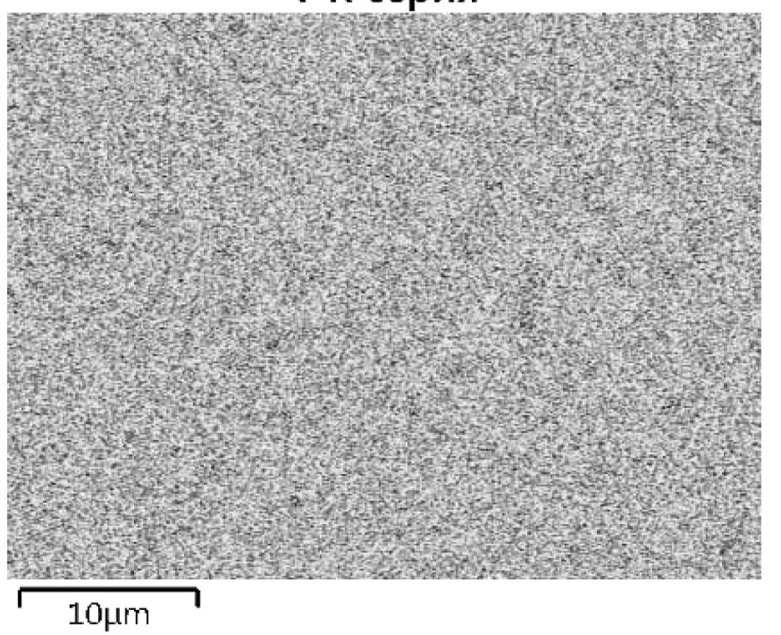

Рис. 7. Результаты РСМА в режиме картирования сплавленного порошка Ti6Al4V (аддитивная технология ЕВМ). Большему содержанию элемента соответствует более интенсивная окраска 
испытаний возможно также применение деталей, изготовленных по аддитивной технологии EBM, вместо штамповок из титановых сплавов.

При изготовлении аддитивных заготовок предпочтительным вектором построения следует выбирать ось Z с учетом напряжений в деталях в процессе эксплуатации.

\section{Литература}

[1] Опыт использования технологии прототипирования для изготовления деталей авиационных агрегатов / А. А. Ильин, С. В. Гаранин, В. В. Кошкин, А. А. Филатов // Литейное производство. - 2007. № 6. - С. 39-41.

[2] Балака Е. В. Основные факторы влияния на процесс формообразования деталей с помощью технологий послойного выращивания (Rapid Prototyping) // Високі технологіi в машинобудуванні: зб. наук. праць. - Харків: НТУ «ХПІ». - 2011. Вип. 1(21). C. $29-36$.

[3] Hohmann M. Production methods and applications for high-quaIity metaI powders and sprayformed product/ Produktionsmethoden und Anwendungen fur qualitativ hochwertige Metallpulver und spruhkompaktierte Halbzeuge / Hohmann M., Brooks G., Spiegelhauer C. // Stahl und Eisen. - 2005.

[4] Tsantrizos P. G. et. al. Method of production of metal and ceramic powders by plasma atomization. Pat. US № 5707419, дата выдачи: 13 янв. 1998.

[5] Зленко М.А. Аддитивные технологии в машиностроении : [учебное пособие для вузов по направле- нию «Технологические машины и оборудование»] / М. А. Зленко, А. А. Попович, И. Н. Мутылина ; М-во образования и науки Рос. Федерации, С.-Петерб. гос. политехн. ун-т. - Санкт-Петербург: Политехнический университет, 2013. - 222 с.

[6] Зленко М. А. Аддитивные технологии в машиностроении / М. А. Зленко, М. В. Нагайцев, В. М. Довбыш // пособие для инженеров. - М.: ГНЦ РФ ФГУП «НАМИ», 2015. - 220 c.

[7] The investigation of the influence of laser remelting on density, surface quality and microstructure of selective laser melting parts / Yasa E. et. al. // Rapid Prototyping Journal. - 2011. - Vol. 17. - Iss: 5. - P. 312327.

[8] Анализ структуры образцов, полученных DMLSи SLM-методами быстрого прототипирования / Безобразов Ю. А. и др. - Екатеринбург, 2012.

[9] Шабров Н. Н. Реальные достижения виртуальной реальности / Н. Н. Шабров // Rational Enterprise Management. - 2011. - № 2 - C.46-48.

[10] Добринский Е. С. Быстрое прототипирование: идеи, технологии, изделия / Е. С. Добринский // Полимерные материалы. - 2011. - № 9. - С. 36-37.

[11] A comparatine study of laser direct metal deposition characteristics using gas and plasma-atomized Ti-6Al-4V powders / Ahsan M. N. et. al. // Materials Science and Engineering. - 2011. - P. 7648-7657.

[12] A comparison of laser additive manufacturing using gas and plasma-atomized Ti-6Al-4V powders / Ahsan M. N. et. al. // Innovative Developments in Virtual and Physical Prototyping. - London: Taylor \& Francis Group, 2012.

Klochikhin V. V. ${ }^{1}$, Rud N. D. ${ }^{1}$, Naumik V. V. ${ }^{2}$, Chigileichik E. V. ${ }^{1}$

${ }^{1}$ Motor Sich, JSC. Ukraine, Zaporozhye

${ }^{2}$ Zaporozhye National Technical University. Ukraine, Zaporozhye

\section{EFFECT OF THE VECTOR OF POWDER MELTING ON THE PROPERTIES OF SAMPLES, MANUFACTURED BY ADDITIVE TECHNOLOGY}

In present study the influences of titanium powder fusion vector on properties of the samples produced by additive technology EBM (Electron Beam Melting) are examined. The advantages of the technology of titanium powder fusion by electron beam in vacuum are shown. The anisotropy of strength and plastic properties has not been established by tests. The impact strength values were significantly higher for samples fused in the Z-axis direction. By results of research the guidelines for EBM technology application in aircraft engine building with choice optimization of fusion vector in titanium blanks production are put out. [dx.doi.org/10.29010/080.9]

Keywords: additive technologies; titanium powders; fusion vector; anisotropy of properties. 


\section{References}

[1] Opyit ispolzovaniya tehnologii prototipirovaniya dlya izgotovleniya detaley aviatsionnyih agregatov / A. A. Ilin, S. V. Garanin, V. V. Koshkin, A. A. Filatov // Liteynoe proizvodstvo. - 2007. - \# 6. - S. 39-41.

[2] Balaka E. V. Osnovnyie faktoryi vliyaniya na protsess formoobrazovaniya detaley s pomoschyu tehnologiy posloynogo vyiraschivaniya (Rapid Prototyping) // Visoki tehnologii v mashinobuduvanni: zb. nauk. prats. - Harkiv: NTU «HPI». - 2011. Vip. 1(21). - S. 29-36.

[3] Hohmann M. Production methods and applications for high-quality metaI powders and sprayformed product/ Produktionsmethoden und Anwendungen fur qualitativ hochwertige Metallpulver und spruhkompaktierte Halbzeuge / Hohmann M., Brooks G., Spiegelhauer C. // Stahl und Eisen. - 2005.

[4] Tsantrizos P. G. et. al. Method of production of metal and ceramic powders by plasma atomization. Pat. US № 5707419, дата выдачи: 13 янв. 1998.

[5] Zlenko M. A. Additivnyie tehnologii v mashinostroenii : [uchebnoe posobie dlya vuzov po napravleniyu «Tehnologicheskie mashinyi i oborudovanie»] / M. A. Zlenko, A. A. Popovich, I. N. Mutyilina ; M-vo obrazovaniya i nauki Ros. Federatsii, S.-Peterb. gos. politehn. un-t. - Sankt-Peterburg: Politehnicheskiy universitet, 2013. - 222 s.

[6] Zlenko M. A. Additivnyie tehnologii v mashinostroenii / M. A. Zlenko, M. V. Nagaytsev, V. M. Dovbyish // posobie dlya inzhenerov. - M.: GNTs RF FGUP «NAMI», 2015. - 220 s.

[7] The investigation of the influence of laser remelting on density, surface quality and microstructure of selective laser melting parts / Yasa E. et. al. // Rapid Prototyping Journal. - 2011. - Vol. 17. - Iss: 5. - P. 312-327.

[8] Analiz strukturyi obraztsov, poluchennyih DMLS- i SLM-metodami byistrogo prototipirovaniya / Bezobrazov Yu. A. i dr. - Ekaterinburg, 2012.

[9] Shabrov N. N. Realnyie dostizheniya virtualnoy realnosti / N. N. Shabrov // Rational Enterprise Management. 2011. - № 2 - S. 46-48.

[10] Dobrinskiy E. S. Byistroe prototipirovanie: idei, tehnologii, izdeliya / E. S. Dobrinskiy // Polimernyie materialyi. 2011. - № 9. - S. 36-37.

[11] A comparatine study of laser direct metal deposition characteristics using gas and plasma-atomized Ti-6Al-4V powders / Ahsan M. N. et. al. // Materials Science and Engineering. - 2011. - P. 7648-7657.

[12] A comparison of laser additive manufacturing using gas and plasma-atomized Ti-6Al-4V powders / Ahsan M. N. et. al. // Innovative Developments in Virtual and Physical Prototyping. - London: Taylor \& Francis Group, 2012. 